\title{
Visual backward masking in retardates and normals'
}

\author{
E. R. JOHNSTONE TRAINING AND RESEARCH CENTER, Bordentown, NJ
}

\begin{abstract}
Educable adolescent male retardates were compared with normal males of equal $C A$ and equal $M A$ on a visual backward masking task. Significantly shorter interstimulus intervals were required to induce a masking effect in the equal-CA group than in the retarded and equal-MA groups, who did not differ from each other. Speed of visual processing is a function of MA. It is related to $C A$ in normals, and to $I Q$ when retardates are compared with equal-CA normals.
\end{abstract}

When the onset of a visual stimulus $\left(S_{2}\right)$ follows immediately or shortly after the offset of another visual stimulus $\left(S_{1}\right)$ at the same point in space, and when $S_{2}$ (the masking stimulus) has appropriate contours, duration, and illumination relative to $S_{1}$, then $S_{1}$ will be inhibited. The blanking of $S_{1}$ by $S_{2}$ is one instance of a phenomenon labelled "backward masking" (see Raab, 1963, for a review). That perception of $S_{1}$ can be voided by an ensuing stimulus indicates that $S_{1}$ requires a period of time after offset for visual processing. As the interstimulus interval (ISI) between $S_{1}$ and $S_{2}$ lengthens, the masking effect of $S_{2}$ weakens. At some point $S_{2}$ no longer interferes with the perception of $S_{1}$.

Backward masking allows for a comparative test of the speed of visual processing by retardates and normals. If retardates take a longer period of time to process a visual stimulus than do normals of equal chronological age (Spitz, 1963), the presentation of $S_{2}$ to retardates must be delayed for a longer interval to prevent its interference with the visual processing of $S_{1}$. The present experiment tests this hypothesis. Of additional interest is the relationship of backward masking to chronological age in normal Ss (Pollack, 1965).

\section{Subjects}

\section{METHOD}

The Ss, all males, were 20 retardates $(R)$ (mean $C A=15.78$, $\mathrm{SD}=.73$; mean $\mathrm{IQ}=63.85, \mathrm{SD}=6.60$ ), residents of a state training school for educable retardates; 20 equal-MA normals (MA) (mean $\mathrm{CA}=9.92, \mathrm{SD}=.66$ ); and 20 equal-CA normals $(\mathrm{CA})$ (mean $\mathrm{CA}=15.18, \mathrm{SD}=.84$ ). The normals were volunteers from a local military institute and from local cub scout packs. No IQs were available for the normals, who were assumed to have approximately average or slightly above average intelligence.

\section{Apparatus and Stimuli}

Stimuli were presented in a three-channel Scientific Prototype Model GB tachistoscope allowing three consecutive presentation times with accuracy of better than $\pm 2 \%$. The test figures $\left(S_{1}\right)$ were the letter D or the letter O. Black Deca-Dry transfer letters were used (Venus Medium style typeface of 60-pt size), and each letter was placed on its own white card. The $D$ was $15 \mathrm{~mm}$ high and 12 $\mathrm{mm}$ wide, the $O$ was $15.5 \mathrm{~mm}$ high and $13 \mathrm{~mm}$ wide. When placed in one channel of the tachistoscope a letter was approximately $121.92 \mathrm{~cm}$ from $\mathrm{S}$ 's eyes and subtended a visual angle of approximately $43 \mathrm{~min}$ in height and $35 \mathrm{~min}$ in width. The dimensions varied slightly, depending on the letter (Fig. 1).

The masking figure $\left(S_{2}\right)$, placed in the second channel of the tachistoscope, was a copy of the pattern that Schiller and Wiener (1963, Fig. 2, Pattern 3) found to be efficient in masking letters. It consisted of a $21 \mathrm{~mm}$ outline square enclosing four parallel diagonal lines that cross-hatched the area enclosed by the square (see Fig. 1). All lines were made by applying matte black 1/32 in. pressure sensitive tape (Chart-Pak) on a white card. The visual
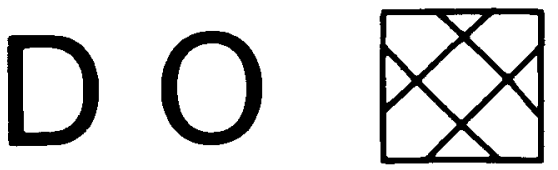

Fig. 1. Test stimuli (D, $O)$ and masking stimulus used in the experiment. angle of the masking pattern was approximately $59 \mathrm{~min}$. The cards were so placed that when the slide holders were seated in the tachistoscope the letter was approximately centered within the area bounded by the masking pattern.

The third channel served as an illuminated pre- and postexposure field and also provided an illuminated ISI. The white card in this field was blank except for four small, lightly-penciled red dots placed to fall at the same point in space as the four outside corners of the masking pattern. The dots defined a fixation area for $\mathrm{S}$.

In order to enhance masking, a high ratio of brightness and exposure duration of the masking pattern to that of the test stimulus was used. The brightness of the masking field was adjusted to $26 \mathrm{ft}-\mathrm{L}$, and the test and blank fields were set at 13 $\mathrm{ft}-\mathrm{L}$, as measured at the eyepiece of the tachistoscope by an Elwood Foto-Meter, Model Z-4. Duration was always $10 \mathrm{msec}$ for the test stimulus and $100 \mathrm{msec}$ for the masking stimulus.

\section{Procedure}

All Ss were screened for near binocular visual acuity on a Bausch and Lomb Modified Ortho-Rater. Only Ss receiving acuity level scores with Snellen equivalents of $20 / 29$ or better were included in the study.

Prior to testing, E showed to S the "O," the "D," and the masking stimulus on separate index cards outside the tachistoscope to assure recognition of the letters. The $S$ was told that the letter $\mathrm{D}$ or $\mathrm{O}$ would be flashed on, followed closely by the design, and that he was to report whether he saw a $\mathrm{D}$, an $\mathrm{O}$, or no letter at all. The choice of a "nothing" response was added primarily because retardates tend to regress to some type of response stereotypy, such as response alternation, when faced with a difficult task to which they cannot give a positive response (Gerjuoy \& Winters, 1967). The instructions gave all Ss a chance to make a relevant response at each presentation. The possibility of response bias will be dealt with in the results section.

To familiarize $S$ with the task, a pretest of six trials was administered: three trials were given at $300 \mathrm{msec}$ ISI, followed by three trials at $150 \mathrm{msec}$ ISI. In a few instances Ss failed a pretest item and the entire pretest was readministered until errorless performance was reached. Repeated errors on the pretest by one $R$ and one MA S indicated that they did not understand or could not perform the task, and they were replaced.

The ISI was varied from 0 to $70 \mathrm{msec}$ in $10 \mathrm{msec}$ steps. In order to shorten the task, half the $\mathrm{Ss}$ in each group received only the "even" ISI durations $(0,20,40,60 \mathrm{msec})$ and half only the "odd" ISI durations $(10,30,50,70 \mathrm{msec})$. A single series consisted of the presentation of each letter twice at each ISI in a pre-set randomized order by the method of constant stimuli. This entire series was repeated after a rest period of approximately 60 sec. Thus, 32 test stimuli were presented to each S.

In addition, four "lie items" were embedded in the presentation, two in each series. For the four lie items, each letter was presented twice at $150 \mathrm{msec}$ ISI. At this ISI masking is unlikely to occur. Consequently, an incorrect response on any of the four lie items was assumed to indicate a failure to understand or follow the instructions. Three R and three MA Ss were dropped from the experiment for this reason and replaced.

Each letter was permanently placed in its own slide holder and, in order to avoid giving cues, one E lifted the slide holder after each trial, regardless of which letter was to follow. A second $E$ set the ISI and gave a verbal "ready" signal prior to each presentation. The pretest did not begin until $S$ could see the four red dots in the pre-exposure field. Perception of these dots indicated that a satisfactory level of dark adaptation had been reached.

No specific feedback was given, but Ss were encouraged throughout the experimental session. Retardates were told that if they did well they would be given a reward, and each was given candy, cigarettes, or a trinket upon completion of the task. Normals were not materially rewarded. 
In sum, there was a total of 36 trials: 32 test trials in which the letter $D$ and the letter $O$ were each presented four times at each of four ISI values, plus four lie items. Each $S$ within a group started at a different point in the series-that is, at a different ISI-and starting points were equated across groups. Viewing was binocular throughout. Testing took place in a dimly lit room.

\section{RESULTS}

A "nothing" response or an incorrect response was scored 0 , a correct response was scored 1 . Lie items were not included in the scoring. Since there were no significant differences between the first and the second series for any of the groups, the total correct responses of the 32 test trials constituted each S's score.

The mean number of correct responses for the $R$ group was $15.85, S D=5.93$, for the MA group 15.25, $S D=3.70$, and for the CA group 20.85, SD $=3.98$. A Duncan multiple range test indicated that the CA group scored significantly higher than both the $R$ and MA groups $(p<.005)$, who did not differ from each other.

Figure 2 shows the performance curves of the three groups. All three curves, smoothed to give the best fit for the data points (Lewis, 1960), describe monotonic, negatively-accelerated functions (Kolers, 1962).

\section{Effects of Practice on Retardates' Performance}

It might be argued that retardates performed more poorly because of anxiety or fear of failure in a novel task. To examine this possibility, six retardates were retested approximately 6 weeks later. The six chosen were the three retardates who scored lowest, highest and at the median in the "even" ISI group, and the three who placed similarly in the "odd" ISI group (see Procedure). To provide incentive, the six Ss were told that if they returned daily for one week they would each receive one dollar.

The results showed no significant change after five extra days of testing. Whereas the average score on original testing had been $15.83, \mathrm{SD}=8.01$, on the final day of testing the average score was $15.33, \mathrm{SD}=6.71$. There were no significant differences on any of the intervening days. Four Ss made more errors on the final day, two made fewer errors. The extra days of practice did not improve the retardates' performance.

\section{The Question of Response Bias}

It is possible that the poorer performance of the lower MA Ss was due to a response bias, e.g., a preference to respond "nothing." Consequently, the percentage of total errors which were "nothing" responses were analyzed for each group and were found to be $67 \%, 71 \%$, and $60 \%$ for the $\mathrm{R}, \mathrm{MA}$, and CA groups, respectively. A Duncan multiple range test, using the percentage of "nothing" responses which contributed to each S's total errors, revealed no significant differences among the groups.

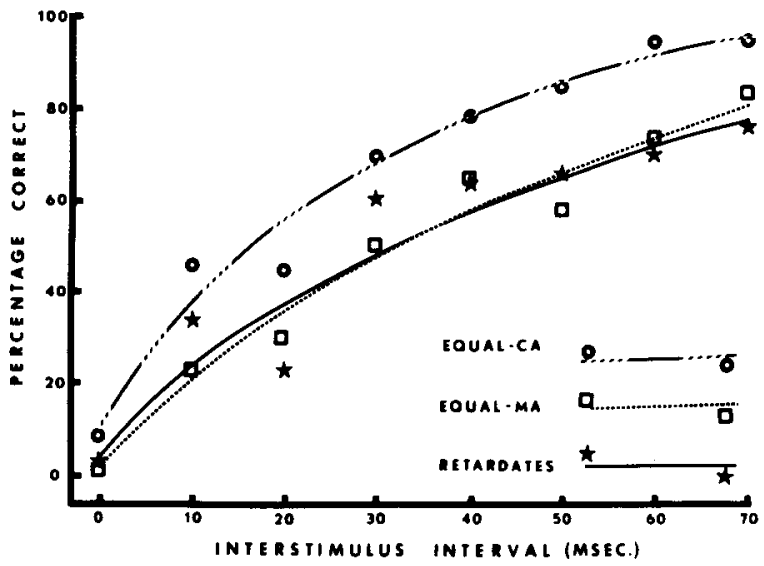

Fig. 2. Percentage of correct responses by three groups as a function of temporal interval between test and masking stimuli. Ten Ss from each group at the 10,30, 50, and 70 ISI points, and 10 at the $0,20,40$, and 60 ISI points. Curves have been smoothed to best fit the data.
Furthermore, the percentages of "nothing" responses declined as ISI increased. Of the total errors made, the R, MA, and CA groups gave $89 \%, 91 \%$, and $81 \%$ "nothing" responses, respectively, at the 0 and $10 \mathrm{msec}$ ISI. At the 60 and $70 \mathrm{msec}$ ISI the "nothing" responses reduced to $28 \%, 19 \%$, and $20 \%$ of the total errors. It seems evident that at the shorter intervals there was complete blanking, while at the longer intervals most errors resulted when Ss judged incorrectly a letter that was only partially perceived because of fragmentary or incomplete masking.

It is interesting to note that in all three groups there were many more instances in which " $O$ " was erroneously called " $D$ " than vice versa. It is possible that this resulted from greater discriminability of slight distortions made by the masking figure on the letter 0 , which might have caused $S$ to believe that he was perceiving the less symmetrical letter.

\section{DISCUSSION}

These results supplement Pollack's finding that the ISI duration necessary for masking decreases from Age 7 to Age 10 (Pollack, 1965). This inverse relationship can be extended to Age 15. However, the present finding that masking interval is also negatively related to intelligence when retardates are compared with normals of equal $\mathrm{CA}$ is contrary to his report of no relationship with IQ. No doubt this is because Pollack used normal Ss and consequently a more restricted IQ range, while we compared two disparate groups.

The equality of performance of the two low-MA groups, when compared with findings using similar populations, suggests that high-grade adolescent retardates perform at the same level as their equal-MA normal counterparts on tasks requiring speed of recognition and short-term memory (Spitz, Hoats, \& Holden, 1968). They perform more poorly on the acquisition of verbal material, and also on spatial discrimination tasks in which cognitive strategies improve performance (Fagan, 1968; Holden, 1967; Spitz, 1967).

\section{REFERENCES}

FAGAN, J. F., IIl. Short-term memory processes in normal and retarded children. J. exp. Child Psychol., 1968, 6, 279-296.

GERJUOY, I. R., \& WINTERS, J. J., Jr. Response preference and choice-sequence preferences: I. Regression to alternation. Psychon. Sci, $1967,7,413-414$.

HOLDEN, E. A., Jr. Stimulus duration and the perception of rectilinear dot progressions in educable retardates. Amer. J. ment. Defic., 1968, 72, 599-602.

KOLERS, P. A. Intensity and contour effects in visual masking. Vision Res, 1962, 2, 277-294.

LEWIS, D. Quantitative methods in psychology. New York: McGraw-Hill, 1960. Pp. 95-97.

POLLACK, R. H. Backward figural masking as a function of chronological age and intelligence. Psychon. Sci., 1965, 3, 65-66.

RAAB, D. H. Backward masking. Psychol. Bull., 1963, 60, 118-129.

SCHILLER, P. H., \& WIENER, M. Monoptic and dichoptic visual masking. J. exp. Psychol, 1963, 66, 386-393.

SPITZ, H. H. Field theory in mental deficiency. In N. R. Ellis (Ed.), Handbook of mental deficiency: Psychological theory and research. New York: McGraw-Hill, 1963. Pp. 11-40.

SPITZ, H. H. Information transmission in an absolute judgment task with feedback, using normal and retarded subjects. J. comp. physiol. Psychol, $1967,72,85-92$.

SPITZ, H. H., HOATS, D. L., \& HOLDEN, E. A., Jr. Numerosity discrimination of tachistoscopically presented dots by mental retardates and normals. Amer. J. ment. Defic., 1968, in press.

\section{NOTE}

1. For permission and assistance in obtaining equal- $S, A$ and equal-MA Ss, we are most grateful to Dr. Harold M. Smith, President, and Mr. John B. Hewett, Headmaster, Bordentown Military Institute; and to the den mothers of cub scout pack 64, Bordentown, N.J., and cub scout pack 100, Willingboro, N.J. We thank the members of the Johnstone Research Department for their critical readings of the manuscript.

(Accepted for publication June 24, 1968.) 